\title{
Hydration of Oxometallate lons in Aqueous Solution
}

\author{
Maciej Śmiechowski and Ingmar Persson*
}

Cite This: Inorg. Chem. 2020, 59, 8231-8239

Read Online

ABSTRACT: The strength of hydrogen bonding to and structure of hydrated oxometallate ions in aqueous solution have been studied by double difference infrared (DDIR) spectroscopy and large-angle X-ray scattering (LAXS), respectively. Anions are hydrated by accepting hydrogen bonds from the hydrating water molecules. The oxygen atom of the permanganate and perrhenate ions form weaker and longer hydrogen bonds to water than the hydrogen bonds in bulk water (i.e., they act as structure breakers), while the oxygen atoms of the chromate, dichromate, molybdate, tungstate, and hydrogenvanadate ions form hydrogen bonds stronger than those in bulk water (i.e., they act as structure makers). The oxometallate ions form one hydration shell distinguishable from bulk water as determined by DDIR spectroscopy and LAXS. The hydration of oxoanions results in $\mathrm{X}-\mathrm{O}$ bond distances ca. $0.02 \AA$ A longer than those in unsolvated ions in the solid state not involved in strong bonding to counterions. The oxygens of oxoanions with

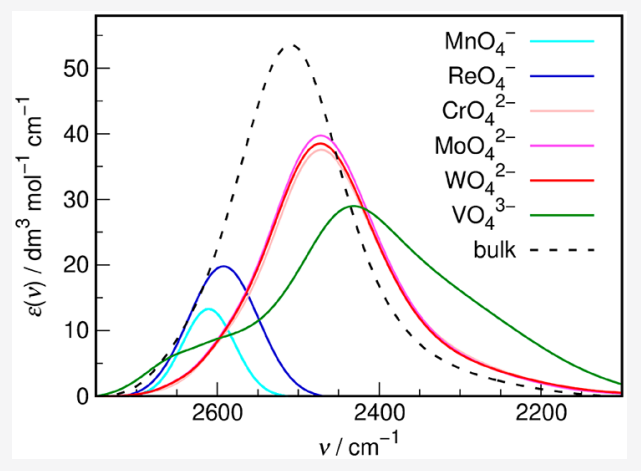
a central atom from the second and third series in the periodic table and the hydrogenvanadate ion hydrogen bind three hydrating water molecules, while oxygens of oxoanions with a heavier central atom only form hydrogen bonds to two water molecules.

\section{INTRODUCTION}

A limited number of methods are available to study the hydration of anions in aqueous solution due to weak hydration and broad distance distribution of the hydrating water molecules. The strength of the hydrogen bonds between an anion and surrounding water molecules is preferably studied by double difference infrared (DDIR) spectroscopy. ${ }^{1}$ Structures of hydrated anions in aqueous solution are preferably studied with large-angle X-ray and neutron scattering, LAXS $^{2}$ and LANS, ${ }^{3}$ respectively. The most commonly applied method to study structures in solution, EXAFS, is normally not applicable as the $\mathrm{X}-(\mathrm{O} \cdots \mathrm{H}-) \mathrm{O}$ distance is long and the distance distribution is wide, which causes the contribution to the EXAFS function to be very small and such distances to be hardly observable. ${ }^{4}$ Furthermore, the hydrogen atom has too weak backscattering ability to be observed accurately. However, LAXS is a very suitable method as it is very sensitive to long distances with a wide bond distance distribution according to the LAXS equation. ${ }^{2}$ Numerous LAXS studies on aqueous solutions have been reported, while only a very limited number of LANS studies on hydrated chloride, bromide, nitrate, and perchlorate ions have been reported. ${ }^{5,6}$

Besides the experimental DDIR and LAXS methods, the hydration of oxoanions has been studied by computational methods. Both static quantum chemical computations and molecular dynamics (MD) simulations (based on ab initio electronic representation or force-field parametrization) have been applied for this purpose. Since the data on nonmetallic oxoanions have been previously reviewed and discussed in detail, $^{7}$ this summary will focus on the few computational investigations devoted specifically to hydrated oxometallate ions. $^{8-11}$ An $a b$ initio MD study on the hydrated permanganate ion in aqueous solution reports an intramolecular $\mathrm{Mn}-\mathrm{O}$ bond length of $1.62 \AA$ and four water molecules at a mean $\mathrm{Mn}(-\mathrm{O}) \cdots \mathrm{O}_{\mathrm{aq}}$ distance of ca. $3.8 \AA$ in a hydration shell characterized as being weak overall. ${ }^{8} \mathrm{~A}$ detailed MD study of the hydrated chromate ion found that it is a moderate structure maker with a coordination number in water of 13-14, with every chromate oxygen forming on average 2.6 hydrogen bonds to water molecules, and a $\mathrm{Cr}-\mathrm{O}$ bond length of $1.61 \AA .9$ An $a b$ initio $\mathrm{MD}$ study of aqueous tungstate revealed that $\mathrm{WO}_{4}{ }^{2-}$ hydrolyzes easily to $\left[\mathrm{WO}_{n}(\mathrm{OH})_{4-n}\right]^{(2-n)-}$ ions that further coordinate up to two additional water molecules in order to reach the $\mathrm{W}$ coordination number of $6 .^{10}$ Finally, static calculations on aqueous vanadate clusters found the intramolecular $\mathrm{V}-\mathrm{O}$ bond length is $1.766 \AA$ in hexahydrate, while the $\mathrm{V}(-\mathrm{O}) \cdots \mathrm{O}_{\mathrm{aq}}$ distance is $2.856 \AA \mathrm{A}^{11}$ The structure parameters and the $\mathrm{O}-\mathrm{D}$ stretching frequencies measured by the DDIR method of the hydrated oxoanions in aqueous solution reported so far are summarized in Table 1.

Hydrated ions are regarded as structure makers or breakers in aqueous solution depending on their ability to form stronger or weaker hydrogen bonds, respectively, to anions or to water

Received: February 24, 2020

Published: May 28, 2020 
Table 1. Summary of Results from DDIR Spectroscopy and LAXS Studies of Oxoanions in Aqueous Solution

\begin{tabular}{|c|c|c|c|c|c|c|c|}
\hline ion & $d(\mathrm{X}-\mathrm{O}) / \AA$ & $d\left(\mathrm{X}-(\mathrm{O}) \cdots \mathrm{O}_{\mathrm{aq}}\right) / \AA$ & $d\left((\mathrm{X}-) \mathrm{O} \cdots(\mathrm{H}-) \mathrm{O}_{\mathrm{aq}}\right) / \AA$ & $\mathrm{X}-\mathrm{O}-\mathrm{O}_{\mathrm{aq}} / \mathrm{deg}$ & $\mathrm{CN}$ & $\nu(\mathrm{O}-\mathrm{D}) / \mathrm{cm}^{-1}$ & refs \\
\hline $\mathrm{NO}_{3}^{-}$ & 1.28 & 3.61 & 3.02 & 107 & 9 & 2595 & $12-15$ \\
\hline $\mathrm{ClO}^{-}$ & 1.662 & 3.85 & 3.045 & 106 & 3 & & 7 \\
\hline $\mathrm{ClO}_{2}^{-}$ & 1.591 & 3.881 & 3.045 & 110 & 6 & & 16 \\
\hline $\mathrm{ClO}_{3}^{-}$ & 1.501 & 3.770 & 3.021 & 108 & 9 & & 16 \\
\hline $\mathrm{ClO}_{4}^{-}$ & 1.453 & 3.757 & 3.046 & 109 & 12 & 2630 & 16 \\
\hline $\mathrm{BrO}_{3}^{-}$ & 1.671 & 4.068 & 2.987 & 119 & 6 & & 16 \\
\hline $\mathrm{IO}_{3}^{-}$ & 1.829 & 4.27 & 3.013 & 122 & 6 & & 16 \\
\hline $\mathrm{IO}_{4}^{-}$ & 1.781 & 4.243 & 3.009 & 123 & 8 & & 16 \\
\hline $\mathrm{SO}_{3}{ }^{2-}$ & 1.53 & 3.68 & 2.878 & 109 & 9 & & 17 \\
\hline $\mathrm{SO}_{4}{ }^{2-}$ & 1.495 & 3.61 & 2.85 & 108 & 12 & 2477 & 18 \\
\hline $\mathrm{S}_{2} \mathrm{O}_{3}{ }^{2-}$ & 1.479 & 3.622 & 2.854 & 109 & 12 & & 19 \\
\hline $\mathrm{SeO}_{3}{ }^{2-}$ & 1.709 & 3.87 & 2.85 & 114 & $6-9$ & 2478 & 20 \\
\hline $\mathrm{SeO}_{4}{ }^{2-}$ & 1.657 & 3.94 & 2.85 & 120 & 8 & 2480 & 20 \\
\hline $\mathrm{H}_{2} \mathrm{PO}_{4}^{-}$ & 1.527 & 3.711 & 2.85 & 111 & 12 & 2478 & 21,22 \\
\hline $\mathrm{HPO}_{4}{ }^{2-}$ & 1.531 & & & & & & 21,22 \\
\hline $\mathrm{PO}_{4}{ }^{3-}$ & 1.533 & & & & & 2434 & 21,22 \\
\hline $\mathrm{H}_{2} \mathrm{AsO}_{3}{ }^{-}$ & 1.785 & 4.096 & 2.85 & 122 & 6 & & 23 \\
\hline $\mathrm{AsO}_{3}{ }^{3-}$ & 1.785 & & & & & & 23 \\
\hline $\mathrm{H}_{2} \mathrm{AsO}_{4}^{-}$ & 1.707 & & & & & & 23 \\
\hline $\mathrm{HAsO}_{4}{ }^{2-}$ & 1.704 & & & & & & 23 \\
\hline $\mathrm{AsO}_{4}{ }^{3-}$ & 1.706 & 3.929 & 2.85 & 121 & 8 & & 23 \\
\hline $\mathrm{WO}_{4}{ }^{2-}$ & 1.786 & 4.06 & 2.83 & 123 & 12 & & 24 \\
\hline $\mathrm{MoO}_{4}{ }^{2-}$ & 1.786 & 4.06 & 2.83 & 123 & 12 & & 24 \\
\hline
\end{tabular}

molecules in the first hydration shell of metal ions in comparison to the intermolecular hydrogen bonds in pure water. ${ }^{25}$ Anions with low charge density, as is the case of most monovalent ions except fluoride and hydroxide, are regarded as water structure breakers, while di- and trivalent anions are regarded as water structure makers. Previous DDIR and structural studies of hydrated anions in aqueous solution show that the $\mathrm{O}-\mathrm{D}$ stretching frequency of hydrating water molecules binding to structure breaking ions is higher than that in pure water, $2510 \mathrm{~cm}^{-1}$, and the $(\mathrm{X}-) \mathrm{O} \cdots(\mathrm{H})-\mathrm{O}$ distances $\left((\mathrm{X}-) \mathrm{O} \cdots \mathrm{O}_{\mathrm{aq}}\right)$ are longer than the $\mathrm{O}(-\mathrm{H}) \cdots \mathrm{O}(-\mathrm{H})$ distances in bulk water $\left(\mathrm{O}_{\mathrm{aq}} \cdots \mathrm{O}_{\mathrm{aq}}\right)$ (Table 1). The $\mathrm{O}-\mathrm{D}$ stretching frequency of the water molecules binding to structure making ions is lower than $2510 \mathrm{~cm}^{-1}$, and the $(\mathrm{X}-) \mathrm{O} \cdots \mathrm{O}_{\mathrm{aq}}$ distances are shorter than $2.89 \AA$. The $\mathrm{X}-\mathrm{O}$, $\mathrm{X}(-\mathrm{O}) \cdots \mathrm{O}_{\mathrm{aq}}$, and $(\mathrm{X}-) \mathrm{O} \cdots \mathrm{O}_{\mathrm{aq}}$ distances are used to calculate the $\mathrm{X}-\mathrm{O} \cdots \mathrm{O}_{\mathrm{aq}}$ bond angle from which the mean number of water molecules hydrogen-bound to each oxoanion oxygen can be estimated with approximately two or three water molecules at $\mathrm{X}-\mathrm{O} \cdots \mathrm{O}_{\mathrm{aq}}$ bond angles of 120 and $109.5^{\circ}$, respectively. It can be observed that oxoanions with a central atom belonging to the second and third row in the periodic table bind three water molecules, while those lower in the periodic table only bind two (cf. Table 1). Whether an oxoanion hydrogen binds two or three water molecules cannot be distinguished in the $\mathrm{O}-\mathrm{D}$ stretching frequencies. For example, the sulfate and selenite ions bind three and two water molecules per oxygen, respectively, but they have the same $\mathrm{O}-\mathrm{D}$ stretching frequency (Table 1).

The aim of this study is to determine the hydrogen bond strength and structure parameters of the hydrated oxometallate anions in aqueous solution and to summarize the present knowledge of the hydration of anions in aqueous solution.

\section{MATERIALS AND METHODS}

Chemicals. Sodium permanganate monohydrate, $\mathrm{NaMnO}_{4} \cdot \mathrm{H}_{2} \mathrm{O}$ (Aldrich, 97\%+), sodium perrhenate, $\mathrm{NaReO}_{4}$ (Aldrich, 99.99\%), sodium chromate tetrahydrate, $\mathrm{Na}_{2} \mathrm{CrO}_{4} \cdot 4 \mathrm{H}_{2} \mathrm{O}$ (Mallinckrodt, p.a.), sodium dichromate dihydrate, $\mathrm{Na}_{2} \mathrm{Cr}_{2} \mathrm{O}_{7} \cdot 2 \mathrm{H}_{2} \mathrm{O}$ (Merck, p.a), sodium molybdate dihydrate, $\mathrm{Na}_{2} \mathrm{MoO}_{4} \cdot 2 \mathrm{H}_{2} \mathrm{O}$ (Merck, p.a.), sodium tungstate dihydrate, $\mathrm{Na}_{2} \mathrm{WO}_{4} \cdot 2 \mathrm{H}_{2} \mathrm{O}$ (Merck, p.a.), and sodium vanadate, $\mathrm{Na}_{3} \mathrm{VO}_{4}$ (Aldrich, 99.98\%) were used as supplied. Heavy water $\left(D_{2} \mathrm{O}, 99.9 \%\right.$ isotopic purity) was supplied by Aldrich.

Solutions. Stock solutions were prepared by dissolving amounts (weighed with $0.1 \mathrm{mg}$ precision) of respective sodium salts in doubledistilled water. For $\mathrm{NaMnO}_{4}, \mathrm{Na}_{2} \mathrm{CrO}_{4}, \mathrm{Na}_{2} \mathrm{MoO}_{4}$, and $\mathrm{Na}_{2} \mathrm{WO}_{4}$, a series of solutions spanning the molality range $\sim 0.2-1.0 \mathrm{~mol} \cdot \mathrm{kg}^{-1}$ were prepared by dissolving weighed amounts of the respective stock solution in double-distilled water. For the $\mathrm{NaReO}_{4}$ and $\mathrm{Na}_{3} \mathrm{VO}_{4}$ salts, only the stock solutions were used for IR spectra measurement. Sample solutions containing HDO were prepared by adding $4 \%$ (by weight) of $\mathrm{D}_{2} \mathrm{O}$ relative to $\mathrm{H}_{2} \mathrm{O}$ and reference solutions by adding the same molar amounts of $\mathrm{H}_{2} \mathrm{O}$. Low fraction of $\mathrm{D}_{2} \mathrm{O}$ is preferable, because the unfavorable equilibrium $\left(\mathrm{H}_{2} \mathrm{O}+\mathrm{D}_{2} \mathrm{O} \rightleftarrows 2 \mathrm{HDO}, K=\right.$ $3.86)^{26}$ must be shifted to the right. In the present case, more than $98 \%$ of OD oscillators are found as HDO, with the additional benefit of providing a convenient raw absorbance value of $\sim 1$ in the $\nu_{\mathrm{OD}}$ stretching vibration maximum. The final salt molalities of the HDO solutions, for which the IR spectra were collected, are reported in Table 2. The concentrations and absorption coefficients of the solutions used in the large-angle $\mathrm{X}$-ray scattering measurements are

Table 2. Salt Molalities $(m)$ of the Solutions Used for DDIR Spectroscopy Measurements

\begin{tabular}{lccccc}
\multicolumn{1}{c}{ solute } & \multicolumn{5}{c}{$m / \mathrm{mol} \mathrm{kg}^{-1}$} \\
$\mathrm{NaMnO}_{4}$ & 0.1856 & 0.3798 & 0.5926 & 0.7880 & 0.9887 \\
$\mathrm{NaReO}_{4}$ & 1.5567 & & & & \\
$\mathrm{Na}_{2} \mathrm{CrO}_{4}$ & 0.1888 & 0.3749 & 0.5723 & 0.7359 & 0.9315 \\
$\mathrm{Na}_{2} \mathrm{MoO}_{4}$ & 0.1848 & 0.3698 & 0.5667 & 0.7497 & 0.9417 \\
$\mathrm{Na}_{2} \mathrm{WO}_{4}$ & 0.1866 & 0.3705 & 0.5682 & 0.7602 & 0.9460 \\
$\mathrm{Na}_{3} \mathrm{VO}_{4}$ & 0.4904 & & & &
\end{tabular}


Table 3. Compositions, pH, Densities $(\rho)$, and Linear Absorption Coefficients $(\mu)$ of the Aqueous Sodium Permanganate, Perrhenate, Chromate, Dichromate, Molybdate, Tungstate, and Vandate Solutions Used in the LAXS Experiments

\begin{tabular}{ccccccr} 
solute & {$\left[\mathrm{XO}_{4}^{-}\right] / \mathrm{mol} \cdot \mathrm{dm}^{-3}$} & {$\left[\mathrm{Na}^{+}\right] / \mathrm{mol}^{-} \cdot \mathrm{dm}^{-3}$} & {$\left[\mathrm{H}_{2} \mathrm{O}\right] / \mathrm{mol}^{-\mathrm{dm}^{-3}}$} & $\mathrm{pH}$ & $\rho / \mathrm{g} \cdot \mathrm{cm}^{-3}$ & $\mu / \mathrm{cm}^{-1}$ \\
$\mathrm{NaMnO}_{4}$ & 1.000 & 1.000 & 52.299 & 12 & 1.0841 & 3.200 \\
$\mathrm{NaReO}_{4}$ & 1.502 & 1.502 & 51.907 & 12 & 1.3457 & 30.170 \\
$\mathrm{Na}_{2} \mathrm{CrO}_{4}$ & 1.502 & 3.004 & 51.882 & 12 & 1.1778 & 3.901 \\
$\mathrm{Na}_{2} \mathrm{Cr}_{2} \mathrm{O}_{7}$ & 1.499 & 2.998 & 50.873 & 5 & 1.2692 & 6.341 \\
$\mathrm{Na}_{2} \mathrm{MoO}_{4}$ & 1.500 & 3.000 & 52.138 & 12 & 1.201 & 10.057 \\
$\mathrm{Na}_{2} \mathrm{WO}_{4}$ & 1.5000 & 3.0000 & 51.882 & 12 & 1.3755 & 28.807 \\
$\mathrm{Na}_{3} \mathrm{VO}_{4}$ & 1.000 & 3.000 & 46.4494 & 12 & 1.1487 & 2.883 \\
\hline
\end{tabular}

summarized in Table 3. The $\mathrm{pH}$ of all solutions except $\mathrm{Na}_{2} \mathrm{Cr}_{2} \mathrm{O}_{7}$ were adjusted to $\mathrm{pH} 12$ with sodium hydroxide to minimize the risk of protonation of the anion. The composition of the vanadate solution at $\mathrm{pH} 12$ is dominated by the $\mathrm{HVO}_{4}{ }^{2-}$ ion, as the $\mathrm{HVO}_{4}{ }^{2-}$ ion is a very weak acid $\left(\mathrm{VO}_{4}{ }^{3-}\right.$ is a strong base) with a $K_{\mathrm{a} 3}$ value of 13.27 in dilute aqueous solution, ${ }^{27}$ giving a composition of ca. $5 \% \mathrm{VO}_{4}{ }^{3-}$ and $95 \%$ $\mathrm{HVO}_{4}{ }^{2-}$ of the studied solution. The other anions studied are much weaker bases and are not protonated at $\mathrm{pH} 12$.

Instruments. FT Infrared Spectrometer. FTIR spectra were recorded on a PerkinElmer $1720 \mathrm{X}$ spectrometer. The measurement cell was equipped with $\mathrm{CaF}_{2}$ windows separated by a Teflon spacer giving a path length of $0.0026 \mathrm{~cm}$, as determined interferometrically. For each spectrum, 256 scans were collected with a resolution of 4 $\mathrm{cm}^{-1}$ and averaged. The temperature in the instrument chamber was $26.5 \pm 0.5^{\circ} \mathrm{C}$.

Large-Angle $X$-ray Scattering. A large-angle $\theta-\theta$ diffractometer was used to measure the scattering of Mo K $\alpha$ radiation, $\lambda=0.7107 \AA$, from the free surface of the aqueous solutions. $\mathrm{Ag} \mathrm{K} \alpha$ radiation, $\lambda=$ $0.5609 \AA$, was used for the molybdate solution as Mo $\mathrm{K} \alpha$ radiation will cause substantial fluorescence radiation in this case. The solutions were contained in a Teflon cuvette inside a radiation shield with beryllium windows. After monochromatization of scattered radiation, by means of a focusing $\mathrm{LiF}$ crystal, the intensity was measured at 450 discrete points in the range of $1^{\circ}<\theta<65^{\circ}$ (the scattering angle is $2 \theta$ ). A total of 100000 counts was accumulated at each angle, and the whole angular range was scanned twice, corresponding to a statistical uncertainty of about $0.3 \%$. The divergence of the primary $\mathrm{X}$-ray beam was limited by 1 or $0.25^{\circ}$ slits for different $\theta$ regions with overlapping some parts of the data for scaling purposes.

All data treatment was carried out using the KURVLR program ${ }^{28}$ which has been described in detail previously. ${ }^{29}$ The experimental intensities were normalized to a stoichiometric unit of volume containing one metal atom in the oxometallate anion, using the scattering factors $f$ for neutral atoms, including corrections for anomalous dispersion, $\Delta f^{\prime}$ and $\Delta f^{\prime \prime},{ }^{30}$ and values for Compton scattering. ${ }^{31,32}$ For a better alignment of the intensity function, a Fourier back-transformation was applied to eliminate spurious (unrelated to any interatomic distances) peaks below $1.2 \AA$ in the radial distribution function. ${ }^{33}$ Least-squares refinements of the model parameters were performed by means of the STEPLR program ${ }^{34}$ to minimize the error square sum $U=\Sigma w(s)\left[i_{\exp }(s)-i_{\text {cal }}(s)\right]^{2}$.

Spectral Data Analysis. The IR spectra were analyzed by the commercial software: GRAMS/32 v. 4.01 (Galactic Industries Corporation, Salem, USA) and RAZOR (Spectrum Square Associates, Inc., Ithaca, USA) run under GRAMS/32. Spectral data were analyzed using the affected spectra method attributed to Stangret et al., 35,36 which is conceptually similar to the one proposed independently by Lindgren and co-workers. ${ }^{1,37,38}$ This numerical procedure leads to the separation of the spectrum of solute-affected water from the bulk water, based on all spectra in the entire solution series and of pure HDO. It has already provided a substantial library of spectral data on ionic solutes, as reviewed previously in detail. ${ }^{39,40}$

The procedure is based on the main assumption that water in the solution can be divided into additive contributions of solute-affected (a) and unaffected bulk (b) water: $\varepsilon c=\varepsilon_{\mathrm{a}} c_{\mathrm{a}}+\varepsilon_{\mathrm{b}} \mathcal{c}_{\mathrm{b}}$ where $\varepsilon_{\mathrm{a}}$ and $\varepsilon_{\mathrm{b}}$ are the molar absorption coefficients $\left(\mathrm{dm}^{3} \mathrm{~mol}^{-1} \mathrm{~cm}^{-1}\right)$ of affected and bulk water, respectively, and $c$ symbols the respective concentrations
( $\mathrm{mol} \mathrm{dm} \mathrm{dm}^{-3}$ ) and $c=c_{\mathrm{a}}+c_{\mathrm{b}}$. The length of sample cell, $l$, is constant in the measurements. Rearranging for $\varepsilon_{\mathrm{a}}$, we obtain

$$
\varepsilon_{\mathrm{a}}=\frac{c}{c_{\mathrm{a}}}\left(\varepsilon-\varepsilon_{\mathrm{b}}\right)+\varepsilon_{\mathrm{b}}
$$

We now introduce the so-called "affected number", $N$, equal to the number of moles of water affected per mole solute. Using it and the known solute molality, $m\left(\mathrm{~mol} \mathrm{~kg}{ }^{-1}\right)$, the concentrations can be expressed the concentrations in eq 1 as $c=1 / M V$ and $c_{\mathrm{a}}=\mathrm{Nm} / \mathrm{V}$, where $M\left(\mathrm{~kg} \mathrm{~mol}^{-1}\right)$ is the mean molar mass of water in the sample $\left(\mathrm{H}_{2} \mathrm{O}+4 \% \mathrm{D}_{2} \mathrm{O}\right)$ and $V\left(\mathrm{dm}^{3}\right)$ is the volume of the solution containing $m$ moles of solute and $1 \mathrm{~kg}$ of water. Substituting into eq 1 the following equation is obtained.

$$
\varepsilon_{\mathrm{a}}=\frac{1}{N M} \frac{\varepsilon-\varepsilon_{\mathrm{b}}}{m}+\varepsilon_{\mathrm{b}}
$$

Equation 2 allows determination of the affected spectrum for a solution of finite molality provided that the $\mathrm{N}$ parameter is known. In this work, it is applied to the $\mathrm{NaReO}_{4}$ and $\mathrm{Na}_{3} \mathrm{VO}_{4}$ solutions, for which only single stock solutions were prepared. In contrast, the advantage of using full solution series for the other solutes and an approximation of the experimental spectra $\varepsilon$ versus $m$ at each discrete wavenumber $\nu_{i}$ by the least-squares method can be performed. This makes it possible to extrapolate the spectrum of solute-affected water to the infinite dilution conditions $(m \rightarrow 0)$ and eq 2 takes the form

$$
\varepsilon_{\mathrm{a}}=\frac{1}{N M}\left(\frac{\partial \varepsilon}{\partial m}\right)_{m=0}+\varepsilon_{\mathrm{b}}
$$

Equations 2 and 3 still contain the hitherto unknown parameter $N$. As mentioned above, it is formally equal to the number of moles of water spectrally affected per mole solute. It should not be directly identified with the "hydration number" or "coordination number" (in the sense of the parameters obtained from diffraction experiments or molecular simulations). $N$ is close to the hydration number derived from direct methods only when the solute-affected HDO band differs significantly from the bulk HDO band, in either position or half-width. ${ }^{36,39}$ Otherwise, the affected number is usually lower than the hydration number, and the solute-affected HDO spectrum carries structural and energetic information about the hydration shell in a "condensed" manner. ${ }^{36}$

The proper value of the affected number can be found either via a band-fitting algorithm ${ }^{35,36}$ or chemometrically. ${ }^{41,42}$ In this work the former method is used, which briefly consists of generating trial solute-affected water spectra for given $N$ values and fitting them using the baseline, analytical bands, and the bulk water spectrum. A mixed Gaussian-Lorentzian product shape is used for the bands. All band parameters are kept unconstrained during the fit, with the exception of the bulk HDO spectrum, for which only intensity is allowed to vary. The maximum value of $N$, for which the solute-affected water spectrum still contains a negligible amount of $\varepsilon_{\mathrm{b}}$, is considered as the "true" value of $N$, and the corresponding $\varepsilon_{\mathrm{a}}$ spectrum is considered the "true" affected water spectrum. The threshold value for $\varepsilon_{\mathrm{b}}$ contribution is set at $\leq 0.5 \%$ of the total integrated intensity of the $\varepsilon_{\mathrm{a}}$ spectrum. As a result of the fitting procedure, both unknowns (i.e., $N$ and $\varepsilon_{\mathrm{a}}$ ) are thus obtained simultaneously. 


\section{RESULTS AND DISCUSSION}

Hydrogen Bonding. The final affected spectra in the $\nu_{\mathrm{OD}}$ stretching vibrations range of $\mathrm{HDO}$ are shown in Figure S1. The corresponding affected numbers can be found in Table 4 .

Table 4. Affected Number $(N)$ of the Studied Sodium Salts, $\nu_{\text {OD }}$ Band Position at Maximum $\left(\nu^{\circ}\right)$, Full Width at HalfHeight $\left(\Delta_{1 / 2}\right)$ of the Anion-Affected HDO Spectrum after the Separation of the $\mathrm{Na}^{+}$-Affected HDO Spectrum, and the Maximum Location of Intermolecular Oxygen-Oxygen Distance Distribution Obtained from the Anion-Affected HDO Spectrum $\left(R_{\mathrm{OO}}{ }^{\circ}\right)$

\begin{tabular}{lrccc}
\multicolumn{1}{c}{ solute } & \multicolumn{1}{c}{$N$} & $\nu^{\circ} / \mathrm{cm}^{-1}$ & $\Delta_{1 / 2} / \mathrm{cm}^{-1}$ & $R_{\mathrm{OO}}{ }^{\circ} / \AA$ \\
pure $\mathrm{HDO}$ & & 2510 & 160 & 2.830 \\
$\mathrm{NaMnO}_{4}$ & 8.8 & 2610 & 78 & 2.976 \\
$\mathrm{NaReO}_{4}$ & 14.9 & 2592 & 103 & 2.968 \\
$\mathrm{Na}_{2} \mathrm{CrO}_{4}$ & 15.1 & 2472 & 167 & 2.791 \\
$\mathrm{Na}_{2} \mathrm{MoO}_{4}$ & 17.5 & 2472 & 167 & 2.791 \\
$\mathrm{Na}_{2} \mathrm{WO}_{4}$ & 17.9 & 2472 & 167 & 2.791 \\
$\mathrm{Na}_{3} \mathrm{VO}_{4}$ & 20.6 & 2432 & 236 & 2.748 \\
\hline
\end{tabular}

As mentioned above, the affected spectra reflect the state of the solute-affected water, and the $N$ parameter is the number of thus perturbed HDO molecules that are spectrally differentiable using the DDIR analysis.

It can immediately be seen that the spectra can be grouped into three distinct classes for monovalent, divalent, and trivalent anions, which are progressively red-shifted with increasing formal charge. This observation is in agreement with the previously found dependencies of the band position on the anion's polarizing power $(q / r$, where $q$ is the ionic charge and $r$ is the ionic radius). ${ }^{23,39,40}$ Notably, the affected spectra for divalent oxoanions are almost identical across the entire group 6 of the periodic table.

The deconvolutions of the affected spectra into analytical bands are shown in Figures 1 and 2. The physical significance of the component bands lies in the representation of the elementary energetic states of water (HDO) underlying the more complex shape of the full spectrum. Thus, OD oscillators in different environments can be readily distinguished. Upon careful examination, these deconvolutions are seen to contain some spurious peaks (i.e., not corresponding to genuine HDO energetic states) that function as either baseline correction, atmospheric $\mathrm{CO}_{2}$ absorption correction, or (in the case of $\mathrm{Na}_{3} \mathrm{VO}_{4}$ ) broad components of the extremely red-shifted affected $\nu_{\mathrm{OH}}$ spectrum; this redshift is also apparent in the $\nu_{\mathrm{OD}}$ range. Therefore, they were eliminated from further analysis, and we proceeded with the genuine affected HDO spectra as seen in Figure 3.

The spectra in Figure 3a contain both anionic and cationic contributions. However, the influence of $\mathrm{Na}^{+}$on the HDO spectrum has been previously studied in detail. ${ }^{37,39,43,44}$ In common with other alkali metals, it shows a slight blueshift of the $\nu_{\mathrm{OD}}$ band to $\sim 2540 \mathrm{~cm}^{-1}$ (i.e., $+30 \mathrm{~cm}^{-1}$ from the maximum of the bulk HDO band at $\left.\sim 2510 \mathrm{~cm}^{-1}\right)$. The influence of the cations on the HDO spectrum was extensively reviewed previously, ${ }^{39}$ and their effect arises primarily from modifying the solvation environment and structure of water molecules in the first hydration shell, as investigated theoretically. ${ }^{45}$ Notably, a careful study of the affected HDO spectrum of $\mathrm{NaPF}_{6}$, containing an extremely structure-breaking hexafluorophosphate anion, led to total separation of the contributions from anion and cation to the affected HDO spectrum, thus delivering an unperturbed $\mathrm{Na}^{+}$-affected spectrum. ${ }^{44}$ This was already successfully used in the extraction of the cationic contribution to $\varepsilon_{\mathrm{a}}$ in the case of $\mathrm{NaOH} .{ }^{46}$

Since the affected HDO spectra for the studied oxoanions contain broad unresolved peaks that mix cationic and anionic contributions, especially in the case of divalent anions (cf. Figure 2), it is extremely difficult to ascribe the analytical component bands to genuine anionic influence. Therefore, the same procedure as that in ref 46 was applied: The separated $\mathrm{Na}^{+}$-affected HDO spectrum from ref 44 was added as an analytical component to the existing fits, and the salt-affected HDO spectrum was refitted allowing only the intensity of the $\mathrm{Na}^{+}$band to vary. Finally, the converged $\mathrm{Na}^{+}$contribution was subtracted, thus providing the anion-affected HDO spectra as shown in Figure $3 \mathrm{~b}$. The most important parameters of these spectra are summarized in Table 2. As expected, the effect of subtraction of the $\mathrm{Na}^{+}$-affected HDO spectrum depends on the overall position of the salt-affected spectrum. For the monovalent anions, for which the spectra in Figure 3a are blue-shifted with respect to that of bulk HDO, the removal of the $\mathrm{Na}^{+}$band reveals more strongly the structure-breaking character of the anion. In contrast, for the di- and trivalent anions, which are seen to red-shift the OD band position, the removal of this band induces further redshift. In any case, the elimination of the cationic influence is beneficial to a deeper understanding of the anionic part of the affected HDO spectrum.

It is informative to compare the obtained results with available data for other oxoanions. In the case of the monovalent ones, perchlorate seems to be a good reference ion. It is well-known that the $\mathrm{ClO}_{4}{ }^{-}$anion is one of the more
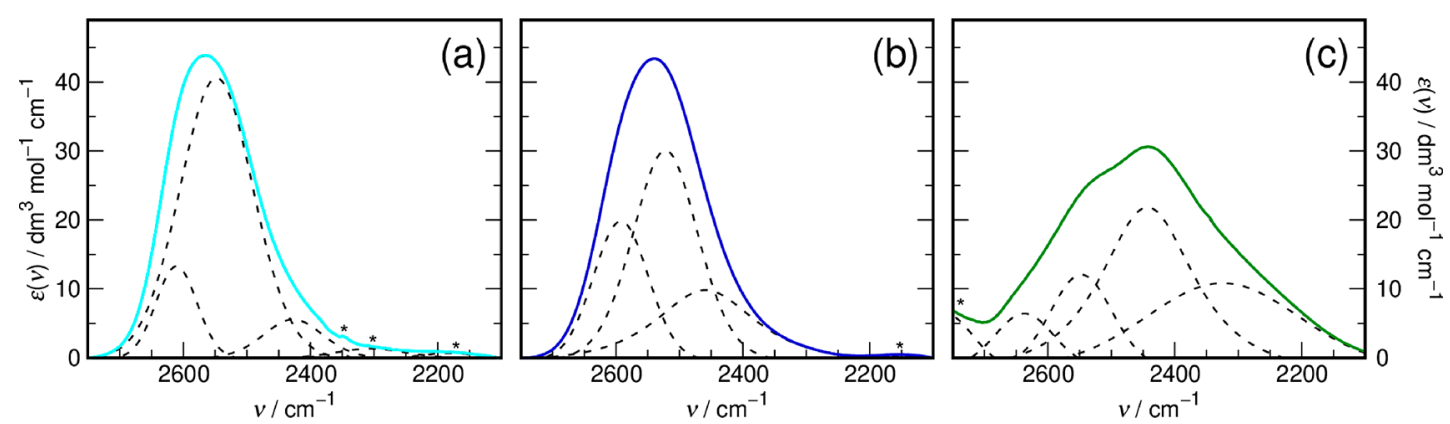

Figure 1. Deconvolution of the solute-affected spectra as shown in Figure $\mathrm{S} 1$ into analytical bands (dashed lines) for (a) $\mathrm{NaMnO}_{4},(\mathrm{~b}) \mathrm{NaReO}_{4}$, and $(c) \mathrm{Na}_{3} \mathrm{VO}_{4}$. Spurious bands not belonging to the $\nu_{\mathrm{OD}}$ vibrations of $\mathrm{HDO}$ are excluded from further analysis and are indicated with an asterisk. 

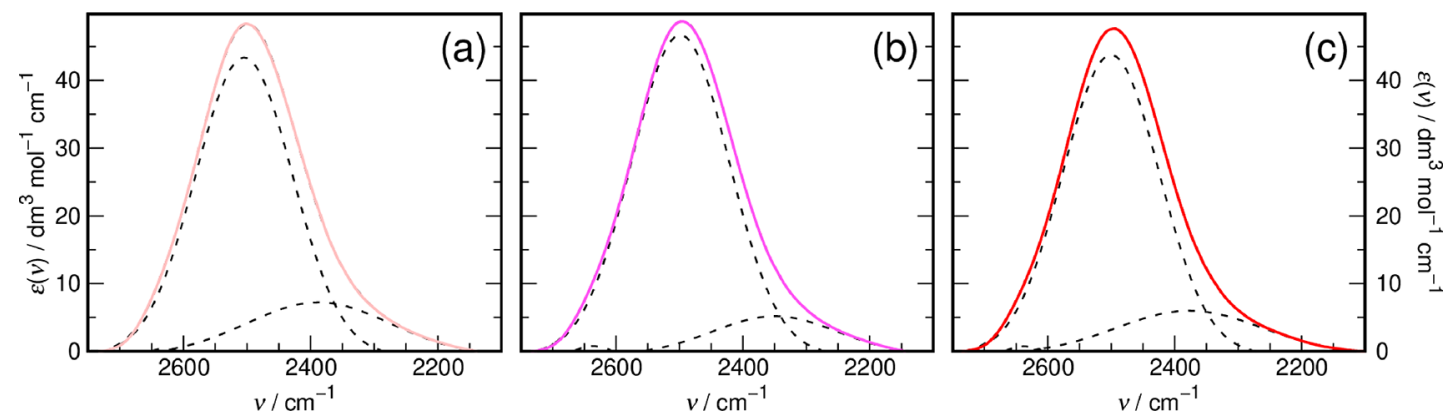

Figure 2. Deconvolution of the solute-affected spectra as shown in Figure $\mathrm{S} 1$ into analytical bands (dashed lines) for $(\mathrm{a}) \mathrm{Na}_{2} \mathrm{CrO}_{4},(\mathrm{~b}) \mathrm{Na}_{2} \mathrm{MoO}_{4}$, and $(c) \mathrm{Na}_{2} \mathrm{WO}_{4}$.
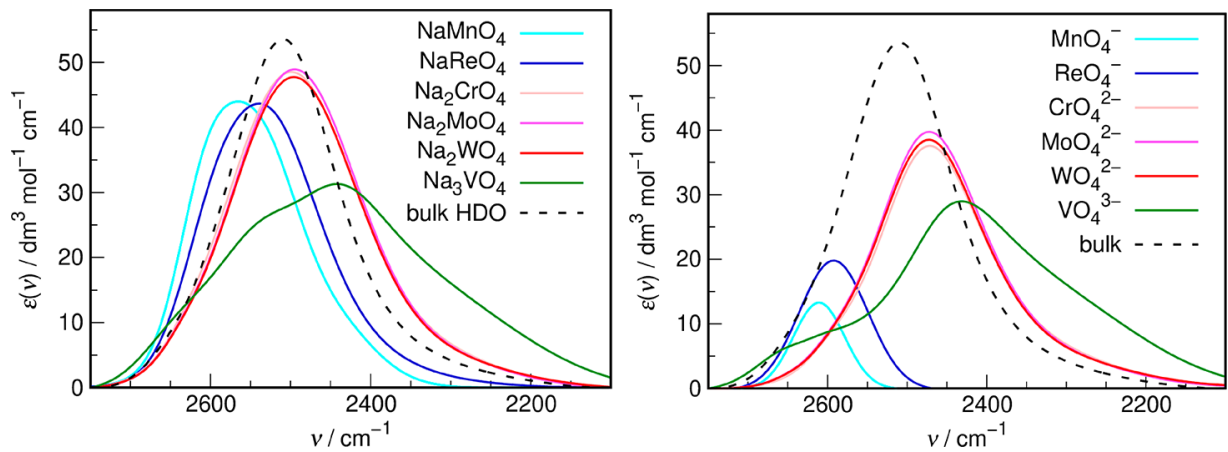

Figure 3. (a) Solute-affected spectra for the studied sodium salts in the $\nu_{\mathrm{OD}}$ stretching vibrations range of HDO after removal of the spurious peaks compared with the bulk HDO spectrum. (b) Separated anion-affected spectra for the studied sodium salts in the $\nu_{\mathrm{OD}}$ stretching vibrations range of HDO after removal of the $\mathrm{Na}^{+}$-affected spectrum contribution as described in the text compared with the bulk HDO spectrum.

structure-breaking ones in aqueous solution. The maximum position of the $\nu_{\mathrm{OD}}$ band $\left(\nu^{\circ}\right)$ is $\sim 2630 \mathrm{~cm}^{-1} \cdot{ }^{15,35,37-39,43}$ Both permanganate and perrhenate are characterized with similar $\nu^{\circ}$ values. Divalent and trivalent anions have been hitherto studied to a much smaller extent. However, the available limited data set corresponds well with the present results. In particular, $\nu^{\circ}=2477$ and $2480 \mathrm{~cm}^{-1}$ for $\mathrm{SO}_{4}{ }^{2-}$ and $\mathrm{SeO}_{4}{ }^{2-}$, respectively, ${ }^{18,20}$ in perfect agreement with our results for the group 6 oxoanions. Similarly, $\nu^{\circ}=2434 \mathrm{~cm}^{-1}$ for $\mathrm{PO}_{4}{ }^{3-}, 22$ the only trivalent anion studied to date, which is strikingly close to our $\nu^{\circ}=2432 \mathrm{~cm}^{-1}$ for $\mathrm{VO}_{4}{ }^{3-}$ (see Table 4$)$, and the affected HDO spectrum is likewise broad and contains underlying features. The full width at half-height of the anion-affected HDO spectrum increases with the increasing red shift of the $\nu_{\mathrm{OD}}$ band. This dependence is linear to a good approximation $\left(\Delta_{1 / 2}=-0.725 \nu^{\circ}+1972, R^{2}=0.91\right)$ and was already detected for a series of simple aqueous anions. ${ }^{16}$ Notably, the results of the previous investigation for some particular anions are in excellent agreement with the current data, viz., $\Delta_{1 / 2}=\sim 75$ $\mathrm{cm}^{-1}$ for $\mathrm{ClO}_{4}^{-}, \sim 170 \mathrm{~cm}^{-1}$ for $\mathrm{SO}_{4}{ }^{2-}$, and $180 \mathrm{~cm}^{-1}$ and for $\mathrm{SeO}_{4}{ }^{2-1} \cdot{ }^{18,20}$

The vanadate anion clearly stands out in the sense that the affected HDO spectrum contains underlying peaks instead of forming a single broad band resembling the bulk HDO spectrum shape. The peak positions at maximum for the three analytical bands are 2324, 2432, and $2638 \mathrm{~cm}^{-1}$, in good agreement with the band parameters previously found for $\mathrm{PO}_{4}{ }^{3-} \cdot{ }^{22}$ On the basis of the cited work, the $2324 \mathrm{~cm}^{-1}$ band is ascribed to strong and short hydrogen bonds from water to the phosphate anion, while the $2432 \mathrm{~cm}^{-1}$ component corresponds to the hydrating waters simultaneously donating two hydrogen bonds to two oxygen atoms in $\mathrm{VO}_{4}{ }^{3-}$. The most blue-shifted component band merits further investigation. At first glance, it is hard to expect severely weakened hydrogen bonds in the vicinity of a strongly hydrated ion. However, the long known concept of anticooperativity of the two hydrogen bonds donated by the same water molecule provides an explanation. ${ }^{47}$ Namely, whenever a water molecule donates to a strong hydrogen bond, the other hydrogen is engaged in a weak hydrogen bond. This particular phenomenon has recently computationally been confirmed for $\mathrm{PO}_{4}{ }^{3-}$, for which the short and strong water-phosphate hydrogen bonds are accompanied by weak hydrogen bonds donated by the same hydrating water molecules to the second hydration shell. ${ }^{48}$ While this explains the appearance of the strongly blue-shifted component band in the anion-affected $\mathrm{HDO}$ spectrum of $\mathrm{VO}_{4}{ }^{3-}$, we should mention another possible phenomenon, namely, the influence of the cation on the outermost hydration sphere of the anion detectable in the affected spectra via the formation of solventseparated ion pairs. This was extensively discussed in the other direction (i.e., the influence of the anion on the cation's outermost hydration sphere), ${ }^{44}$ but the same mechanism is expected to arise here. We note that the two explanations are not mutually exclusive.

A more direct comparison of HDO spectra with structural data is made possible by transforming the molar absorptivity band contour $\varepsilon_{\mathrm{a}}(\nu)$ to the probability distribution of the intermolecular oxygen-oxygen distance $P\left(R_{\mathrm{OO}}\right)$. It is based on the generalization of the empirical relationship noted previously between $\nu_{\mathrm{OD}} / \nu_{\mathrm{OH}}$ band positions of HDO in solid hydrates and the respective intermolecular distances determined by diffraction methods. ${ }^{49}$ The details of the $\varepsilon\left(\nu_{\mathrm{OD}}\right) \rightarrow$ $P\left(R_{\mathrm{OO}}\right)$ transformation are published elsewhere. ${ }^{36,37}$ In brief, it is based on the relation between $R_{\mathrm{OO}}$ and $\nu_{\mathrm{OD}}$ found in solid 
hydrates, ${ }^{49}$ which is of the form $R_{\mathrm{OO}}=[16.01-\ln (2727-$ $\left.\left.\nu_{\mathrm{OD}}\right)\right] / 3.73$. The band contour is then transformed to the probability distribution by inverting this relation and taking the derivative according to

$$
P\left(R_{\mathrm{OO}}\right)=C \varepsilon\left(v_{\mathrm{OD}}\right)\left(\mathrm{d} v_{\mathrm{OD}} / \mathrm{d} R_{\mathrm{OO}}\right)
$$

where the normalization constant $C$ is chosen such that the probability distribution is properly normalized to unity.

The obtained probability distributions based on the anionaffected HDO spectra are shown in Figure 4 and are compared

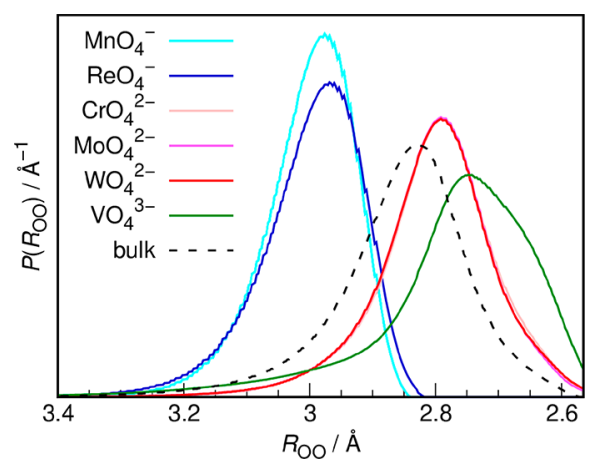

Figure 4. Intermolecular oxygen-oxygen distance distributions derived from the anion-affected HDO spectra shown in Figure 3 compared to the respective distribution in bulk HDO. The curves for the three divalent anions are almost superimposed.

with bulk water. We note that intermolecular oxygen-oxygen distance distributions for oxoanions contain contributions stemming both from anion-water and water-water (in the hydration shell) hydrogen bonds. On the basis of the data in Figure 4, we can reiterate the strongly structure breaking character of the studied monovalent anions, contrasting of the mildly structure-making divalent anions of group 6 and the more-structure-making vanadate.

Structure Determination in Aqueous Solution. The LAXS data show that the hydrated oxometallate ions bind one shell of water molecules to the oxygen atoms. The $\mathrm{M}-\mathrm{O}$ and $\mathrm{M}-(\mathrm{O}) \cdots \mathrm{O}_{\mathrm{aq}}$ distances have been determined very accurately as they are not superimposed with other distances. However, for di- and trivalent oxometallate ions, the $(\mathrm{M}-) \mathrm{O} \cdots \mathrm{O}_{\mathrm{aq}}$ distance is too close to the bulk $\mathrm{O}_{\mathrm{aq}} \cdots \mathrm{O}_{\mathrm{aq}}$ distance to be separated from each other, while for the permanganate and perrhenate ions it is sufficiently longer to be separated from of the bulk $\mathrm{O}_{\mathrm{aq}} \cdots \mathrm{O}_{\mathrm{aq}}$ contribution. The mean $\mathrm{O}_{\mathrm{aq}} \cdots \mathrm{O}_{\mathrm{aq}}$ distance in LAXS studies of fairly concentrated (ca. $1 \mathrm{~mol} \cdot \mathrm{dm}^{-3}$ ) aqueous solution is ca. $2.89(2) \AA \AA^{2,50}$ while it is slightly shorter in pure water, ca. $2.85 \AA \AA^{51}$ For the divalent anions it was not possible to separate the $\mathrm{O} \cdots \mathrm{O}_{\mathrm{aq}}$ and $\mathrm{O}_{\mathrm{aq}} \cdots \mathrm{O}_{\mathrm{aq}}$ distances, and they were refined as a mean value slightly shorter than $2.89 \AA$. This indicates an $\mathrm{O} \cdots \mathrm{O}_{\mathrm{aq}}$ distance of ca. $2.85 \AA$ that has been used in the calculations of the $\mathrm{M}-\mathrm{O}-\mathrm{O}$ bond angles. All oxoanions in this study except the hydrogenvanadate hydrogen bind on average two water molecules to each oxoanion oxygen, while hydrogenvanadate ion binds three water molecules per vanadate oxygen. This is in line with previous observations that oxoanions with a central atom belonging to series 4 or higher only hydrogen bind two water molecules to each oxoanion oxygen. The hydrogenvanadate ion is the exception binding three water molecules per oxygen. The refined structure parameters of the hydrated permanganate, perrhenate, chromate, dichromate, molybdate, tungstate, and hydrogenvanadate ions in aqueous solution as determined by LAXS are summarized in Table 5, and the fitting of the raw

Table 5. Mean Bond Distances (d), Number of Distances $(N)$, and Temperature Coefficients $(b)$ in the LAXS Studies of Aqueous Sodium or Lithium Oxometallate Solutions at Room Temperature ${ }^{a}$

\begin{tabular}{|c|c|c|c|c|}
\hline species & interaction & $N$ & $d / \AA ̊$ & $b / \AA^{2}$ \\
\hline \multirow{3}{*}{$\mathrm{HVO}_{4}{ }^{2-}$} & $\mathrm{V}-\mathrm{O}$ & 4 & $1.738(2)$ & $0.0014(2)$ \\
\hline & $\mathrm{V}-(\mathrm{O}) \cdots \mathrm{O}_{\mathrm{aq}}$ & 12 & $3.754(4)$ & $0.0262(7)$ \\
\hline & $\mathrm{V}-\left(\mathrm{O} \cdots \mathrm{O}_{\mathrm{aq}}\right) \cdots \mathrm{O}_{\mathrm{aq}}$ & 24 & $4.323(3)$ & $0.0390(6)$ \\
\hline \multirow{2}{*}{$\begin{array}{l}\mathrm{Na}\left(\mathrm{H}_{2} \mathrm{O}\right)_{6}^{+} \\
\text {water bulk }\end{array}$} & $\mathrm{Na}-\mathrm{O}$ & 6 & $2.43(2)$ & $0.018(2)$ \\
\hline & $\mathrm{O}_{\mathrm{aq}} \cdots \mathrm{O}_{\mathrm{aq}}$ & 2 & $2.891(3)$ & $0.0185(5)$ \\
\hline \multirow{2}{*}{$\mathrm{CrO}_{4}^{2-}$} & $\mathrm{Cr}-\mathrm{O}$ & 4 & $1.660(3)$ & $0.0021(2)$ \\
\hline & $\mathrm{Cr}-(\mathrm{O}) \cdots \mathrm{O}_{\mathrm{aq}}$ & 8 & $3.955(5)$ & $0.0242(8)$ \\
\hline \multirow{2}{*}{$\begin{array}{l}\mathrm{Na}\left(\mathrm{H}_{2} \mathrm{O}\right)_{6}^{+} \\
\text {water bulk }\end{array}$} & $\mathrm{Na}-\mathrm{O}$ & 6 & $2.432(9)$ & $0.0187(12)$ \\
\hline & $\mathrm{O}_{\mathrm{aq}} \cdots \mathrm{O}_{\mathrm{aq}}$ & 2 & $2.886(2)$ & $0.0174(3)$ \\
\hline \multirow{4}{*}{$\mathrm{Cr}_{2} \mathrm{O}_{7}^{2-}$} & $\mathrm{Cr}-\mathrm{O}_{\mathrm{t}}$ & 2 & $1.616(6)$ & $0.0019(5)$ \\
\hline & $\mathrm{Cr}-\mathrm{O}_{\mathrm{b}}$ & 2 & $1.806(6)$ & $0.0029(7)$ \\
\hline & $\mathrm{Cr} \cdots \mathrm{Cr}$ & 0.5 & $3.211(8)$ & $0.0044(8)$ \\
\hline & $\mathrm{Cr}-\left(\mathrm{O}_{\mathrm{b}}\right) \cdots \mathrm{O}_{\mathrm{aq}}$ & 4 & $3.72(1)$ & $0.024(1)$ \\
\hline \multirow{3}{*}{$\begin{array}{l}\mathrm{Na}\left(\mathrm{H}_{2} \mathrm{O}\right)_{6}^{+} \\
\text {water bulk }\end{array}$} & $\mathrm{Cr}-\left(\mathrm{O}_{\mathrm{t}}\right) \cdots \mathrm{O}_{\mathrm{aq}}$ & 2 & $3.92(1)$ & $0.026(1)$ \\
\hline & $\mathrm{Na}-\mathrm{O}$ & 6 & $2.42(2)$ & $0.020(2)$ \\
\hline & $\mathrm{O}_{\mathrm{aq}} \cdots \mathrm{O}_{\mathrm{aq}}$ & 2 & $2.880(5)$ & $0.0191(8)$ \\
\hline \multirow{2}{*}{$\mathrm{MoO}_{4}{ }^{2-}$} & $\mathrm{Mo}-\mathrm{O}$ & 4 & $1.775(4)$ & $0.0032(4)$ \\
\hline & $\mathrm{Mo}-(\mathrm{O}) \cdots \mathrm{O}_{\mathrm{aq}}$ & 8 & $4.010(3)$ & $0.0245(4)$ \\
\hline \multirow{2}{*}{$\begin{array}{l}\mathrm{Li}\left(\mathrm{H}_{2} \mathrm{O}\right)_{4}^{+} \\
\text {water bulk }\end{array}$} & $\mathrm{Li}-\mathrm{O}$ & 4 & $1.96(2)$ & $0.010(2)$ \\
\hline & $\mathrm{O}_{\mathrm{aq}} \cdots \mathrm{O}_{\mathrm{aq}}$ & 2 & $2.881(2)$ & $0.0202(3)$ \\
\hline \multirow{2}{*}{$\mathrm{WO}_{4}^{2-}$} & $\mathrm{W}-\mathrm{O}$ & 4 & $1.797(4)$ & $0.0021(3)$ \\
\hline & $\mathrm{W}-(\mathrm{O}) \cdots \mathrm{O}_{\mathrm{aq}}$ & 8 & $4.024(4)$ & $0.0230(5)$ \\
\hline \multirow{2}{*}{$\begin{array}{l}\mathrm{Na}\left(\mathrm{H}_{2} \mathrm{O}\right)_{6}^{+} \\
\text {water bulk }\end{array}$} & $\mathrm{Na}-\mathrm{O}$ & 6 & $2.429(17)$ & $0.0202(15)$ \\
\hline & $\mathrm{O}_{\mathrm{aq}} \cdots \mathrm{O}_{\mathrm{aq}}$ & 2 & $2.886(3)$ & $0.0173(4)$ \\
\hline \multirow{2}{*}{$\mathrm{MnO}_{4}^{-}$} & $\mathrm{Mn}-\mathrm{O}$ & 4 & $1.630(5)$ & $0.0024(5)$ \\
\hline & $\mathrm{Mn}-(\mathrm{O}) \cdots \mathrm{O}_{\mathrm{aq}}$ & 8 & $4.095(8)$ & $0.0352(4)$ \\
\hline \multirow{3}{*}{$\begin{array}{l}\mathrm{Na}\left(\mathrm{H}_{2} \mathrm{O}\right)_{6}^{+} \\
\text {water bulk } \\
\text { water bulk }\end{array}$} & $\mathrm{Na}-\mathrm{O}$ & 6 & $2.428(14)$ & $0.019(2)$ \\
\hline & $\mathrm{O}_{\mathrm{MnO} 4} \cdots \mathrm{O}_{\mathrm{aq}}$ & 2 & $3.031(8)$ & $0.038(1)$ \\
\hline & $\mathrm{O}_{\mathrm{aq}} \cdots \mathrm{O}_{\mathrm{aq}}$ & 2 & $2.889(2)$ & $0.0212(3)$ \\
\hline \multirow{2}{*}{$\mathrm{ReO}_{4}^{-}$} & $\mathrm{Re}-\mathrm{O}$ & 4 & $1.735(2)$ & $0.0022(4)$ \\
\hline & $\mathrm{Re}-(\mathrm{O}) \cdots \mathrm{O}_{\mathrm{aq}}$ & 8 & $4.197(7)$ & $0.0377(4)$ \\
\hline $\mathrm{Na}\left(\mathrm{H}_{2} \mathrm{O}\right)_{6}^{+}$ & $\mathrm{Na}-\mathrm{O}$ & 6 & $2.43(2)$ & $0.018(2)$ \\
\hline water bulk & $\mathrm{O}_{\mathrm{ReO} 4} \cdots \mathrm{O}_{\mathrm{aq}}$ & 2 & $3.01(4)$ & $0.025(8)$ \\
\hline water bulk & $\mathrm{O}_{\mathrm{aq}} \cdots \mathrm{O}_{\mathrm{aq}}$ & 2 & $2.881(7)$ & $0.0209(12)$ \\
\hline
\end{tabular}

${ }^{a}$ The estimated standard deviations given within parentheses include only statistical errors.

data and radial distribution function (RDF) of the sodium perrhenate solution is shown in Figure 5. The fittings of the remaining solutions are shown in Figures S2-S7.

Due to the hydration, the $\mathrm{M}-\mathrm{O}$ bond distances become almost $0.02 \AA$ longer in aqueous solution than those in solid compounds where the oxometallate anions are not binding any metal ion other than alkali metal ions or organic cations or molecules; see Tables 6 and S1. We note that the charge neutralization of the oxygens of the oxometallate anions through the hydrogen bonding of the hydrating water 

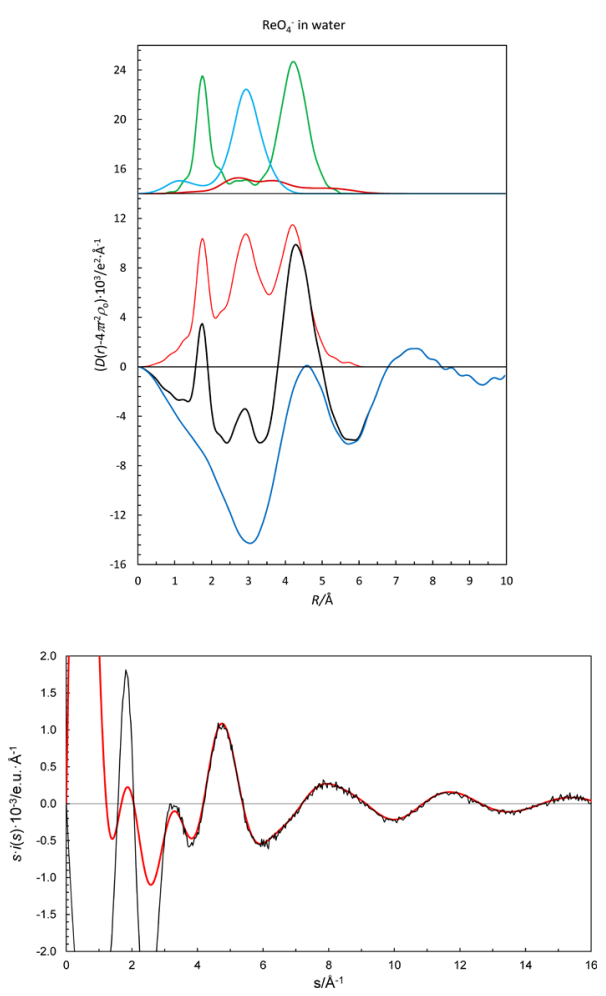

Figure 5. Top panel: LAXS radial distribution curves for a $1.502 \mathrm{~mol}$. $\mathrm{dm}^{-3}$ aqueous solution of sodium perrhenate. (Upper part) Separate model contributions (offset: 14) of the hydrated perrhenate ion (green line), the hydrated sodium ion (brown line) and aqueous bulk (light blue line). (Middle part) Experimental RDF: $D(r)-4 \pi r^{2} \rho_{\mathrm{o}}$ (black line); sum of model contributions (red line); difference (blue line). Bottom panel: Reduced LAXS intensity functions $s \cdot i(s)$ (black line); model $s \cdot i_{\text {calc }}(s)$ (red line).

Table 6. Mean M-O Bond Distance in Oxometallate Anions in the Solid State (without Strong Bonds to the Oxometallate Oxygens) and Aqueous Solution ${ }^{a}$

\begin{tabular}{clll} 
& $d(\mathrm{M}-\mathrm{O})(\mathrm{s}) / \AA$ & $d(\mathrm{M}-\mathrm{O})(\mathrm{aq}) / \AA$ & \multicolumn{1}{c}{ diff. } \\
$\mathrm{VO}_{4}{ }^{3-}$ & 1.720 & 1.738 & 0.018 \\
$\mathrm{CrO}_{4}{ }^{2-}$ & 1.643 & 1.660 & 0.017 \\
$\mathrm{Cr}_{2} \mathrm{O}_{7}{ }^{2-}$ & $1.608+1.782$ & $1.616+1.806$ & $0.012+0.024$ \\
$\mathrm{MoO}_{4}{ }^{2-}$ & 1.756 & 1.775 & 0.019 \\
$\mathrm{WO}_{4}{ }^{2-}$ & 1.776 & 1.797 & 0.021 \\
$\mathrm{MnO}_{4}{ }^{-}$ & 1.611 & 1.630 & 0.019 \\
$\mathrm{ReO}_{4}{ }^{-}$ & 1.709 & 1.735 & 0.026 \\
$a_{\text {Tables S1 and }}$ S5, respectively. & & \\
\end{tabular}

molecules seems to be independent of the charge of the anion even though the hydrogen bond strength is different.

\section{CONCLUSIONS}

Anions are hydrated by accepting hydrogen bonds from the hydrating water molecules. Monovalent anions, except fluoride and hydroxide, form hydrogen bonds to water which are weaker and longer than the hydrogens bonds in bulk water (i.e., they act as structure breakers), while the fluoride, hydroxide, and di- and trivalent anions form hydrogen bonds stronger than those in bulk water (i.e., they act as structure makers). The anions form one hydration shell distinguishable from bulk water, as also determined by DDIR spectroscopy and LAXS. The hydration of oxoanions results in $\mathrm{X}-\mathrm{O}$ bonds ca. $0.02 \AA$ longer than those of unsolvated ions in the solid state not involved in strong bonding to counterions as metal ions except the alkali metal ions (Tables 6 and S1). The oxygens of oxoanions with a central atom from the second and third series in the periodic table and hydrogenvanadate hydrogen bind three hydrating water molecules, while oxygens of oxoanions with a heavier central atom only hydrogen bind two water molecules (Tables 1 and 5).

\section{ASSOCIATED CONTENT}

\section{Supporting Information}

The Supporting Information is available free of charge at https://pubs.acs.org/doi/10.1021/acs.inorgchem.0c00594.

Summary of metal-oxygen bond distances in reported crystal structures containing oxometallate ions not binding to a metal ion, except alkali metal ions. Double difference infrared spectra of HDO solutions of sodium oxometallates. Radial distribution functions and reduced intensity functions of the LAXS studies of the aqueous solutions of sodium permanganate, chromate, dichromate, molybdate, tungstate, and hydrogenvanadate (PDF)

\section{AUTHOR INFORMATION}

\section{Corresponding Author}

Ingmar Persson - Department of Molecular Sciences, Swedish University of Agricultural Sciences, SE-750 07 Uppsala,

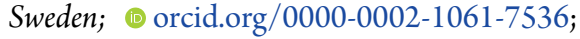

Email: ingmar.persson@slu.se

\section{Author}

Maciej Śmiechowski - Department of Physical Chemistry, Chemical Faculty, Gdansk University of Technology, PL-80-233 Gdansk, Poland

Complete contact information is available at: https://pubs.acs.org/10.1021/acs.inorgchem.0c00594

\section{Notes}

The authors declare no competing financial interest.

\section{ACKNOWLEDGMENTS}

The support from the Swedish Research Council is gratefully acknowledged. We acknowledge funding from the statutory fund of the Chemical Faculty, Gdańsk University of Technology. The support to M.S. from the Visby Programme through the Swedish Institute for his stay in Uppsala is gratefully acknowledged.

\section{REFERENCES}

(1) Kristiansson, O.; Eriksson, A.; Lindgren, J. Hydration of Ions in Aqueous Solutions Studied by Infrared Spectroscopy. I. Method. Acta Chem. Scand. 1984, 38a, 609-612.

(2) Johansson, G. Structures of complexes in solution derived from X-ray diffraction measurements. Adv. Inorg. Chem. 1992, 39, 159232.

(3) Neilson, G. W. Diffraction studies of aqueous electrolyte solutions. Pure Appl. Chem. 1988, 60, 1797-1806.

(4) Teo, B. K. EXAFS: Basic Principles and Data Analysis EXAFS; Springer-Verlag, GmbH Co., Berlin, 2013.

(5) Ansell, S.; Barnes, A. C.; Mason, P. E.; Neilson, G. W.; Ramos, S. $\mathrm{X}$-ray and neutron scattering studies of the hydration structure of alkali ions in concentrated aqueous solutions. Biophys. Chem. 2006, 124, 171-179. and references therein. 
(6) Ohtaki, H.; Radnai, T. Structure and Dynamics of Hydrated Ions. Chem. Rev. 1993, 93, 1157-1204. and references therein.

(7) Eklund, L. Hydration of Oxo Anions. A Combined Computational and Experimental Structure and Dynamics Study in Aqueous Solutions. Doctoral Thesis, Swedish University of Agricultural Sciences, Uppsala, Sweden, 2014 (available at https://pub.epsilon. slu.se/11192/).

(8) Bühl, M. Structure, Dynamics, and Magnetic Shieldings of Permanganate Ion in Aqueous Solution. A Density Functional Study. J. Phys. Chem. A 2002, 106, 10505-10509.

(9) Hinteregger, E.; Pribil, A. B.; Hofer, T. S.; Randolf, B. R.; Weiss, A. K. H.; Rode, B. M. Structure and Dynamics of the Chromate Ion in Aqueous Solution. An ab Initio QMCF-MD Simulation. Inorg. Chem. 2010, 49, 7964-7968.

(10) Rodríguez-Fortea, A.; Vilà-Nadal, L.; Poblet, J. M. Hydration of Hydrogentungstate Anions at Different $\mathrm{pH}$ Conditions: A CarParrinello Molecular Dynamics Study. Inorg. Chem. 2008, 47, 77457750.

(11) Pye, C. C.; Walker, V. E. J. Ab Initio Investigation of the Hydration of the Tetrahedral Perchlorate, Perbromate, Selenate, Arsenate, and Vanadate Anions. J. Phys. Chem. A 2011, 115, 1300713015.

(12) Caminiti, R.; Cucca, P.; Radnai, T. Investigation on the Structure of Cadmium Nitrate Aqueous Solutions by X-ray Diffraction and Raman-spectroscopy. J. Phys. Chem. 1984, 88, 2382-2386.

(13) Caminiti, R.; Atzei, D.; Cucca, P.; Anedda, A.; Bongiovanni, G. Structure of Rhodium(III) Nitrate Aqueous Solutions - An Investigation by X-ray Diffraction and Raman Spectroscopy. J. Phys. Chem. 1986, 90, 238-243.

(14) Caminiti, R.; Licheri, G.; Piccaluga, G.; Pinna, G. $\mathrm{NO}_{3}-\mathrm{H}_{2} \mathrm{O}$ Interactions in aqueous-solutions. J. Chem. Phys. 1978, 68, 19671970.

(15) Bergström, P.-Å.; Lindgren, J.; Kristiansson, O. An IR study of the hydration of perchlorate, nitrate, iodide, bromide, chloride and sulfate anions in aqueous solution. J. Phys. Chem. 1991, 95, 85758580.

(16) Eklund, L.; Hofer, T. S.; Persson, I. Structure and water exchange of hydrated oxo halo ions in aqueous solution using QMCF MD simulation, large angle X-ray scattering and EXAFS. Dalton Trans. 2015, 44, 1816-1828.

(17) Eklund, L.; Hofer, T. S.; Pribil, A.; Rode, B. M.; Persson, I. On the Structure and Dynamics of the Hydrated Sulfite Ion in Aqueous Solution - An ab initio QMCF MD Simulation and Large Angle X-ray Scattering Study. Dalton Trans. 2012, 41, 5209-5216.

(18) Vchirawongkwin, V.; Rode, B. M.; Persson, I. Structure and Dynamics of Sulfate Ion in Aqueous Solution - An ab initio QMCF MD Simulation and Large Angle X-Ray Scattering Study. J. Phys. Chem. B 2007, 111, 4150-4155.

(19) Eklund, L.; Hofer, T. S.; Weiss, A. K. H.; Tirler, A. O.; Persson, I. Detailed structure elucidation of the hydrated thiosulfate ion using QMCF MD simulation and large angle X-ray scattering in aqueous solution. Dalton Trans. 2014, 43, 12711-12720.

(20) Eklund, L.; Persson, I. Structure and Hydrogen Bonding of the Hydrated Selenite and Selenate Ions in Aqueous Solution. Dalton Trans. 2014, 43, 6315-6321.

(21) Persson, I.; Trublet, M.; Klysubun, W. Structure Determination of Phosphoric Acid and Phosphate Ions in Aqueous Solution Using EXAFS Spectroscopy and Large Angle X-ray Scattering. J. Phys. Chem. A 2018, 122, 7413-7420.

(22) Smiechowski, M.; Gojło, E.; Stangret, J. Systematic Study of Hydration Patterns of Phosphoric(V) Acid and Its Mono-, Di-, and Tripotassium Salts in Aqueous Solution. J. Phys. Chem. B 2009, 113, $7650-7661$.

(23) Mähler, J.; Persson, I.; Herbert, R. B. Structure and Hydrogen Bonding of Arsenic Oxyacid Species in Aqueous Solution. Dalton Trans. 2013, 42, 1364-1377.

(24) Johansson, G.; Caminiti, R. The Hydration of Tungstate and Molybdate Ions in Aqueous Solution. Z. Naturforsch., A: Phys. Sci. 1986, 41A, 1325-1329.
(25) Marcus, Y. Effect of Ions on the structure of Water. Structure Making and Breaking. Chem. Rev. 2009, 109, 1346-1370.

(26) Duplan, J. C.; Mahi, L.; Brunet, J. L. NMR determination of the equilibrium constant for the liquid $\mathrm{H}_{2} \mathrm{O}-\mathrm{D}_{2} \mathrm{O}$ mixture. Chem. Phys. Lett. 2005, 413, 400-403.

(27) Cruywagen, J. J.; Heyns, J. B. B. Vanadium(V) equilibria. Spectrophotometric and enthalpimetric investigation of the dimerization and deprotonation of $\mathrm{HVO}_{4}{ }^{2-}$. Polyhedron 1991, 10, 249-253.

(28) Johansson, G.; Sandström, M. Computer-programs for analysis of data on X-ray-diffraction by liquids. Chem. Scr. 1973, 4, 195-198.

(29) Stålhandske, C. M. V.; Persson, I.; Sandström, M.; KamienskaPiotrowicz, E. A Large Angle Scattering and Vibrational Spectroscopic Study of the Solvated Zinc, Cadmium and Mercury(II) Ions in $\mathrm{N}, \mathrm{N}$ Dimethylthioformamide Solution. Inorg. Chem. 1997, 36, 3174-3182.

(30) International Tables for X-ray Crystallography; Kynoch Press: Birmingham, U.K., 1974; Vol. 4.

(31) Cromer, D. T. Compton Scattering Factors for Aspherical Free Atoms. J. Chem. Phys. 1969, 50, 4857-4859.

(32) Cromer, D. T.; Mann, J. B. Compton Scattering Factors for Spherically Symmetric Free Atoms. J. Chem. Phys. 1967, 47, 18921893.

(33) Levy, H. A.; Danford, M. D.; Narten, A. H. Data Collection and Evaluation with an X-ray Diffractometer Designed for the Study of Liquid Structure; Technical Report ORNL-3960; Oak Ridge National Laboratory: Oak Ridge, TN, 1966.

(34) Molund, M.; Persson, I. STEPLR - A Program for Refinements of Data on X-Ray Scattering by Liquids. Chem. Scr. 1985, 25, 197197.

(35) Stangret, J. Solute-affected vibrational-spectra of water in $\mathrm{Ca}\left(\mathrm{ClO}_{4}\right)_{2}$ aqueous-solutions. Spectrosc. Lett. 1988, 21, 369-381.

(36) Stangret, J.; Gampe, T. Hydration Sphere of Tetrabutylammonium Cation. FTIR Studies of HDO Spectra. J. Phys. Chem. B 1999, $103,3778-3783$

(37) Kristiansson, O.; Eriksson, A.; Lindgren, J. Hydration of Ions in Aqueous Solutions Studied by Infrared Spectroscopy. II. Application. Acta Chem. Scand. 1984, 38a, 613-618.

(38) Kristiansson, O.; Lindgren, J.; de Villepin, J. A quantitative infrared spectroscopic method for the study of the hydration of ions in aqueous solutions. J. Phys. Chem. 1988, 92, 2680-2685.

(39) Stangret, J.; Gampe, T. Ionic Hydration Behavior Derived from Infrared Spectra of HDO. J. Phys. Chem. A 2002, 106, 5393-5402.

(40) Śmiechowski, M.; Stangret, J. Vibrational spectroscopy of semiheavy water (HDO) as a probe of solute hydration. Pure Appl. Chem. 2010, 82, 1869-1887.

(41) Bruździak, P.; Panuszko, A.; Stangret, J. Chemometric determination of solute-affected solvent vibrational spectra as a superior way of information extraction on solute solvation phenomena. Vib. Spectrosc. 2010, 54, 65-71.

(42) Bruździak, P.; Rakowska, P. W.; Stangret, J. Chemometric Method of Spectra Analysis Leading to Isolation Lysozyme and CtDNA Spectra Affected by Osmosis. Appl. Spectrosc. 2012, 66, $1302-1310$.

(43) Stangret, J.; Kamieńska-Piotrowicz, E. Effect of tetraphenylphosphonium and tetraphenylborate ions on the water structure in aqueous solutions; FTIR studies of HDO spectra. J. Chem. Soc., Faraday Trans. 1997, 93, 3463-3466.

(44) Gojło, E.; Smiechowski, M.; Stangret, J. Ionic Hydration in $\mathrm{LiPF}_{6}, \mathrm{NaPF}_{6}$, and $\mathrm{KPF}_{6}$ Aqueous Solutions Derived from Infrared HDO Spectra. J. Phys. Chem. B 2004, 108, 15938-15943.

(45) Pejov, L.; Spångberg, D.; Hermansson, K. Using MD Snapshots in ab Initio and DFT Calculations: $\mathrm{OH}$ Vibrations in the First Hydration Shell around $\mathrm{Li}^{+}(\mathrm{aq})$. J. Phys. Chem. A 2005, 109, 51445152.

(46) Śmiechowski, M.; Stangret, J. Hydroxide Ion Hydration in Aqueous Solutions. J. Phys. Chem. A 2007, 111, 2889-2897.

(47) Luck, W. A. P.; Klein, D.; Rangsriwatananon, K. Anticooperativity of the two water OH groups. J. Mol. Struct. 1997, 416, 287-296. 
(48) Sharma, B.; Chandra, A. Ab Initio Molecular Dynamics Simulation of the Phosphate Ion in Water: Insights into Solvation Shell Structure, Dynamics, and Kosmotropic Activity. J. Phys. Chem. B 2017, 121, 10519-10529.

(49) Berglund, B.; Lindgren, J.; Tegenfeldt, J. On the correlation between deuteron quadrupole coupling constants, $\mathrm{O}-\mathrm{H}$ and $\mathrm{O}-\mathrm{D}$ stretching frequencies and hydrogen-bond distances in solid hydrates. J. Mol. Struct. 1978, 43, 179-191.

(50) Jalilehvand, F.; Spångberg, D.; Lindqvist-Reis, P.; Hermansson, K.; Persson, I.; Sandström, M. Hydration of the Calcium Ion. An EXAFS, Large Angle X-ray Scattering and Molecular Dynamics Simulation Study. J. Am. Chem. Soc. 2001, 123, 431-441.

(51) Nilsson, A.; Pettersson, L. G. M. Perspective on the structure of liquid water. Chem. Phys. 2011, 389, 1-34. 